\section{Observational evidence of climate change on extreme events over East Africa}

\author{
Joshua Ngaina, Berthwel Mutai \\ Department of Meteorology, University \\ of Nairobi, Kenya
}

\section{Abstract}

Examination of trend patterns of rainfall and temperature extremes over East Africa (EA) was based on graphical, regression and Mann-Kendall test approaches, while perturbations of rainfall, sunspot activity (SA) and southern oscillation index (SOI) extremes were computed using moving average methods. Annual total rainfall generally decreased with heavy and extreme precipitation rates confined within short spells during wet days. Observed maximum temperature extremes increased while minimum temperature extremes decreased with a statistically significant rise in the number of hot days and warm nights and a decrease in number of cool days and cold nights. However, space-time pattern of observed changes were not well organized. Perturbations of rainfall, SA and SOI indicated that extreme values were changing with increasing frequency and magnitude. Similarities in observed rainfall over EA illustrated the existence of homogeneous zones of climate change clustered as either coastal (with SA dominant), lake Victoria (unique to both SA and SOI), dry continental (SOI) or wet continental areas (both SA and SOI dominant).

\section{Introduction}

Climate exerts a significant control on the day-to-day economic development of Africa, particularly for the agricultural and waterresources sectors, at regional, local and household scales. The climate of the Africa continent is controlled by complex maritime and terrestrial interactions that produce a variety of climates across a range of regions such as the humid tropics. Other studies across the globe concerning climate extremes and their variation, intensities and frequencies indicate the significant influence of climate change. Climate change is expected to place considerable additional stress on the biophysical, economic, political and social systems that determine livelihood security in Africa. ${ }^{1}$

Observed temperature trends have shown consistent greater warming since the 1960 s over Africa. ${ }^{2}$ However, these changes are not always uniform. For instance, decadal warming rates of $0.29^{\circ} \mathrm{C}$ in the African tropical forests have been observed. ${ }^{3}$ Rainfall has been noted to exhibit spatial and temporal variability ${ }^{4}$ with great inter-annual rainfall variability over most of Africa. In some regions, multidecadal variability is also substantial. Over EA, decreasing trends in temperature from weather stations located close to the coast or to major inland lakes have been observed. ${ }^{5}$ During recent decades, EA has been experiencing an intensifying dipole rainfall pattern on the decadal time-scale characterised by increasing rainfall over the northern sector and declining amounts over the southern sector. ${ }^{6}$ Observed extremes including drought and floods have long contributed to human migration, cultural separation, population dislocation and the collapse of prehistoric and early historic societies ${ }^{7}$ with one-third of the people in Africa living in drought-prone areas and vulnerable to the impacts of droughts. For example, several million people regularly suffer impacts from droughts and floods which are exacerbated by health problems, particularly diarrhoea, cholera and malaria. ${ }^{8}$ During the mid-1980s, the economic losses from droughts totalled several hundred million US dollars. ${ }^{9}$ Droughts have mainly affected the Sahel, the Horn of Africa and Southern Africa, particularly since the end of the 1960 s. $^{10}$

Floods are also critical and impact on African development. Recurrent floods in some countries are linked, in some cases, to ENSO events. Occurrence of such events results to important economic and human losses. ${ }^{11}$ Even countries located in dry areas such as Algeria, Tunisia, Egypt, and Somalia have not been flood-free. ${ }^{12}$

The probable changes in mean and extreme precipitation in EA estimated from global climate models (GCMs) show substantial evidence in support of a positive shift of the whole rainfall distribution during the wet seasons. ${ }^{13}$ These models have indicated an increase in mean precipitation rates and intensity of high rainfall events, but less severe droughts. However, the increase in precipitation in the tropics has been found not to be zonally uniform, with $E A$ precipitation projected to increase more than the zonal mean in the multi-model mean. ${ }^{13}$

East Africa is very vulnerable to the extreme climate events including the recurrent droughts, floods, intense hot and dry spells. With economies and livelihoods of most countries over EA being highly weather dependent, ${ }^{14}$ the observed spatial-temporal variability extreme events are associated to adverse effects in agricultural, water sector, horticultural and tourism industries. ${ }^{15}$ These last limit the socio-political and economical development of countries as they redirect most of their scarce resources to disaster response and
Correspondence: Joshua Ngaina, Department of Meteorology, University of Nairobi, Riverside Drive, 30197-00100, Nairobi, Kenya.

Tel. +254.20.4449004 - Fax: +254.20.4449902.

E-mail: jngaina@gmail.com

Key words: rainfall, temperature, extremes, sunspot activity, southern oscillation index.

Conflict of interests: the authors declare no potential conflict of interests.

Contributions: the authors contributed equally.

Acknowledgments: the authors would like to thank the University of Nairobi for providing support during the study and the national Meteorological and Hydrological Centres including Kenya, Uganda, Tanzania and Rwanda for providing data used for the study.

Received for publication: 14 January 2013. Accepted for publication: 21 May 2013.

This work is licensed under a Creative Commons Attribution 3.0 License (by-nc 3.0).

(c)Copyright J. Ngaina and B. Mutai, 2013

Licensee PAGEPress, Italy

Global Meteorology 2013; 2:e2

doi:10.4081/gm.2013.e2

recovery as well as relief programs.

Therefore, concerns about climate change are real. As all communities try to get adapted to the challenges of their local climate, they are today sensitive to its variations. ${ }^{16}$ For example, temperature changes involving a rise of about $1.2^{\circ} \mathrm{C}$ above the mean temperature and the resulting changes in precipitation and soil moisture would cause large areas such as land that now support tea cultivation in Kenya to be largely unusable. Moreover, it is expected that persistence of warm and rainy days will increase the incidence of malaria events. ${ }^{17}$ Temperature warming in formerly cooler, higher-elevation East African highlands, subsequently may lead to the spread of malaria to populations that had not previously been frequently exposed to the disease. ${ }^{18}$

Extreme weather or climate events affect vulnerability to future extreme events by modifying resilience, coping and adaptive capacity. ${ }^{19}$ In particular, the cumulative effects of disasters at local or sub-national levels can substantially affect livelihood options and resources and the capacity of societies and communities to prepare for and respond to future disasters. A changing climate leads to changes in the frequency, intensity, spatial extent, duration, and timing of extreme weather and climate events, can result in unprecedented extreme weather and climate events. Changes in extremes can be linked to changes in the mean, variance, or shape of probability 
distributions..$^{19}$

Considerable effort has been devoted to investigating possible changes in mean climate, and increasingly to changes in variability and extremes. Therefore, this study aims to identify the observational trends in extreme temperature and rainfall over EA. With extreme climate events resulting to adverse macro socio-economic implications affecting the livelihoods of populations, ${ }^{20}$ adapting to these events will require the knowledge of their frequency and severity. Such information is needed for proper planning and can only be deduced from long records of data of the past and present. ${ }^{21}$ The urgent need for realistic adaptation options is aimed at reducing the vulnerability of the environment, wildlife and human and support economic systems to cope with the consequences of recurrent climate extremes, variability and climate change.

\section{Materials and Methods}

\section{Study area}

East Africa region comprises Kenya, Uganda, Tanzania, Rwanda and Burundi as shown in Figure 1. The larger EA region lies between latitudes $12^{\circ} \mathrm{S}$ and $5^{\circ} \mathrm{N}$ and between longitudes $28^{\circ} \mathrm{E}$ and $42^{\circ} \mathrm{E}$. East Africa has a distinct bimodal rainfall pattern which is influenced by the inter tropical convergence zone (ITCZ), global oceans, the tropical high pres-

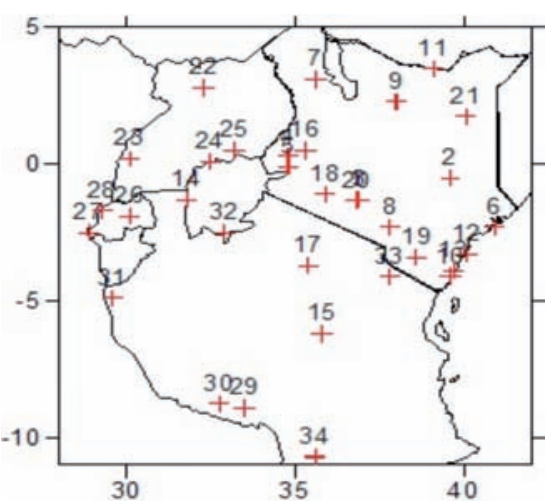

Figure 1. Location of the stations referred to in this study.

Table 1. Regression for precipitation indices of selected stations with daily observed data.

\begin{tabular}{|c|c|c|c|c|c|c|c|c|c|c|c|c|}
\hline Stations & Latitude & Longitude & Time (years) & RX1 day & RX5 day & RX 10 & RX 20 & CDD & CWD & R95p & R99p & $\begin{array}{l}\text { Precipitation } \\
\text { (Total) }\end{array}$ \\
\hline Dagoretti & -1.3 & 36.8 & 1967-2009 & -0.18 & 0.88 & 0.05 & 0.04 & 0.22 & 0.01 & 0.24 & -0.17 & 1.37 \\
\hline Dodoma & -6.2 & 35.8 & $1970-2003$ & 0.77 & 0.75 & 0.06 & 0.06 & 0.98 & 0.01 & 2.81 & 2.56 & 3.41 \\
\hline Eldoret & 0.5 & 35.3 & 1993-2009 & 0.17 & 0.38 & -0.06 & 0.09 & 0.35 & -0.21 & 2.38 & 0.23 & -5.21 \\
\hline Kericho & -3.7 & 35.4 & 1967-2009 & 1.18 & 0.95 & -0.85 & -0.24 & -0.16 & 0.07 & 8.52 & 3.95 & -7.52 \\
\hline Kigoma & -4.9 & 29.6 & $1970-2003$ & -0.43 & -0.17 & -0.20 & 0.03 & 2.27 & 0.06 & 3.99 & 0.51 & -5.40 \\
\hline Kisumu & -0.1 & 34.8 & 1993-2009 & 0.15 & -1.06 & -0.13 & 0.02 & 0.90 & -0.12 & -3.08 & -3.19 & -3.41 \\
\hline Lodwar & 3.7 & 35.6 & $1967-2009$ & 0.02 & -0.50 & -0.05 & -0.02 & -0.92 & -0.04 & -0.29 & 0.68 & -1.29 \\
\hline Makindu & -2.3 & 37.9 & 1968-2009 & 0.07 & -0.30 & -0.07 & -0.04 & 0.93 & 0.02 & 0.82 & -0.40 & -1.40 \\
\hline Narok & -1.1 & 35.8 & 1991-2009 & 0.29 & 0.29 & -0.03 & 0.13 & 0.03 & 0.05 & -0.52 & 1.02 & -0.11 \\
\hline Same & -4.1 & 37.8 & $1970-2003$ & -0.54 & -0.36 & -0.05 & -0.03 & 0.83 & -0.03 & -2.06 & -1.21 & -3.43 \\
\hline Songea & -10.7 & 35.6 & $1970-2003$ & -0.16 & -0.64 & -0.27 & -0.12 & -0.32 & -0.08 & -0.61 & -0.64 & -0.65 \\
\hline \multicolumn{4}{|c|}{ Stations with positive tendency (\%) } & 54 & 50 & 15 & 46 & 62 & 46 & 46 & 46 & 15 \\
\hline \multicolumn{4}{|c|}{ Stations with negative tendency (\%) } & 31 & 46 & 69 & 38 & 23 & 38 & 38 & 38 & 69 \\
\hline
\end{tabular}

RX1day, monthly maximum one day precipitation; RX5day, monthly maximum consecutive five day precipitation; RX10, annual count of days when precipitation is greater than $10 \mathrm{~mm}$; RX20, annual count of days when precipitation is greater than $20 \mathrm{~mm}$; CDD, consecutive dry days; CWD, consecutive wet days; R95p, annual total precipitation greater than the $95^{\text {th }}$ percentile; R99p, annual total precipitation greater than the $99^{\text {th }}$ percentile.

Table 2. Regression for temperature indices of selected stations with daily observed data.

\begin{tabular}{lcccccccccccccccc} 
Stations Latitude Longitude lime (years) & TXx & TXn & TNx & TNn & TX10p & TX90p & TNx10p TNn90p & WSDI & CSDI & DINR \\
Bukoba & -1.3 & 31.8 & $1970-2003$ & -0.03 & 0.03 & 0.05 & 0.00 & -0.25 & 0.23 & -0.02 & 0.40 & 0.12 & 0.05 & 0.04 \\
Dagoretti & -1.3 & 36.8 & $1967-2009$ & 0.02 & 0.02 & 0.04 & 0.08 & -0.20 & 0.07 & -0.64 & 0.80 & -0.04 & -0.25 & -0.03 \\
\hline Dodoma & -6.2 & 35.8 & $1970-2003$ & 0.09 & 0.05 & -0.03 & -0.02 & 0.02 & -0.01 & 0.66 & 0.01 & 0.13 & 1.39 & 0.02 \\
Kericho & -3.7 & 35.4 & $1967-2009$ & 0.02 & -0.05 & 0.09 & -0.06 & 0.01 & 0.39 & -0.08 & 0.34 & 0.67 & -0.14 & 0.00 \\
\hline Kigoma & -4.9 & 29.6 & $1970-2003$ & 0.05 & 0.05 & - & - & - & - & - & - & - & - & - \\
Kisumu & -0.1 & 34.8 & $1993-2009$ & 0.00 & -0.19 & 0.00 & -0.14 & 0.02 & 0.33 & -0.18 & 0.21 & 0.52 & -0.06 & -0.01 \\
\hline Lodwar & 3.7 & 35.6 & $1967-2009$ & 0.03 & 0.04 & 0.02 & 0.01 & -0.45 & 0.54 & -0.31 & 0.33 & 0.06 & -0.36 & 0.01 \\
Makindu & -2.3 & 37.9 & $1968-2009$ & 0.02 & 0.01 & 0.03 & -0.02 & -0.35 & 0.44 & -0.24 & 0.44 & 0.12 & -0.09 & 0.01 \\
\hline Mwanza & -2.5 & 32.9 & $1970-2003$ & 0.06 & 0.04 & 0.04 & -0.04 & -0.34 & 0.40 & 0.90 & -0.19 & 0.17 & 1.57 & 0.09 \\
Narok & -1.1 & 35.8 & $1991-2009$ & -0.03 & 0.02 & -0.08 & 0.17 & 0.01 & 0.33 & -0.08 & 0.35 & 0.86 & -0.24 & -0.03 \\
\hline Same & -4.1 & 37.8 & $1970-2003$ & 0.02 & 0.02 & -0.04 & -0.01 & 0.02 & 0.16 & 0.85 & -0.69 & 0.10 & 0.80 & 0.05 \\
Songea & -10.7 & 35.6 & $1970-2003$ & -0.05 & 0.05 & -0.01 & 0.09 & -0.31 & 0.23 & -0.39 & 0.48 & 0.09 & -0.16 & 0.01 \\
\hline Stations with positive tendency (\%) & & 8 & 10 & 7 & 4 & 5 & 10 & 3 & 8 & 10 & 4 & 7 \\
Stations with negative tendency (\%) & & 3 & 2 & 4 & 6 & 6 & 1 & 8 & 2 & 1 & 7 & 3 \\
\hline
\end{tabular}

TXX, annual maximum value of daily maximum temperature; TXn, annual minimum value of daily maximum temperature; TNx, annual maximum value of daily minimum temperature; TNn, annual minimum value of daily minimum temperature; TX10p, percentage of days when TX $<10^{\text {th }}$ percentile; TX90p, percentage of days when TX $>90^{\text {th }}$ percentile; TNx $10 \mathrm{p}$, percentage of days when TNX $<10$ th percentile; TNn90p, percentage of days when $\mathrm{TNn}>90^{\text {th }}$ percentile; WSDI, warm spell duration indicator; CSDI, cold spell duration indicator; DTR, daily temperature range. 
sure systems (Mascarene, St. Helena, Azores and Arabian), tropical monsoons and tropical cyclones. ${ }^{22}$

The ITCZ occurs over the region twice a year $^{23}$ and has much influence on the rainfall pattern due to its quasi-continuous belt of unsettled, often rainy weather around the tropics, sandwiched between generally fine weather to the north and south of the subtropical highs. ${ }^{21}$ East Africa has complex terrain that includes the high mountains as Kilimanjaro, Kenya and Ruwenzori as well as the Great Rift Valley which runs North-South across the region and has several lakes that include Bogoria, Turkana, Tanganyika, and Elmenteita. Lake Victoria, the second largest freshwater lake after lake Superior, ${ }^{24}$ is also found in the region.

Other factors that influence precipitation and temperature over the region include intraseasonal 30-60 day Madden-Julian waves, easterly waves, tropical storms, extra-tropical weather systems teleconnections with globalscale climatic anomalies linked to sea surface temperatures (SSTs), the quasi-biennial oscillation (QBO) in the equatorial lower stratospheric zonal wind, solar and lunar forcing. ${ }^{25} \mathrm{El}$ Niño southern oscillation index (ENSO), through its two phases - the warm phase El Niño and the cold phase La Niña - also affects the rainfall pattern.

Temperatures in EA are moderate except in the hot and generally humid coastal belt, the arid and semi arid lands, with maximums of around $25^{\circ} \mathrm{C}$ and minimums of $15^{\circ} \mathrm{C}$ at an altitude of $1500 \mathrm{~m}$. The rainfall pattern over the region is diverse. Over much of this area, the major rainfall periods are concentrated within two peak seasons of March-May and OctoberDecember referred to as long rains and short rains, respectively. Parts of the western and coastal regions also receive significant rainfall during the months of July-August, controlled by the seasonal migration of ITCZ.

\section{Data}

East Africa region comprises Kenya, Uganda, Tanzania, Daily and monthly station observed data were used. They included maximum and minimum temperature and rainfall totals. These were obtained from the National Meteorological and Hydrological Services (NMHSs) in the region which includes Kenya, Uganda, Tanzania and Rwanda, as shown in Appendix A. These data will cover the period 1961 to 2009. Sunspot activity (SA) and southern oscillation index (SOI) data for the period 1900 to 2010 was used to indicate the climate variability of $\mathrm{EA}$.

\section{Methodology}

Time series analysis was achieved through graphical method and involved plotting original unsmoothed times series data. Monthly
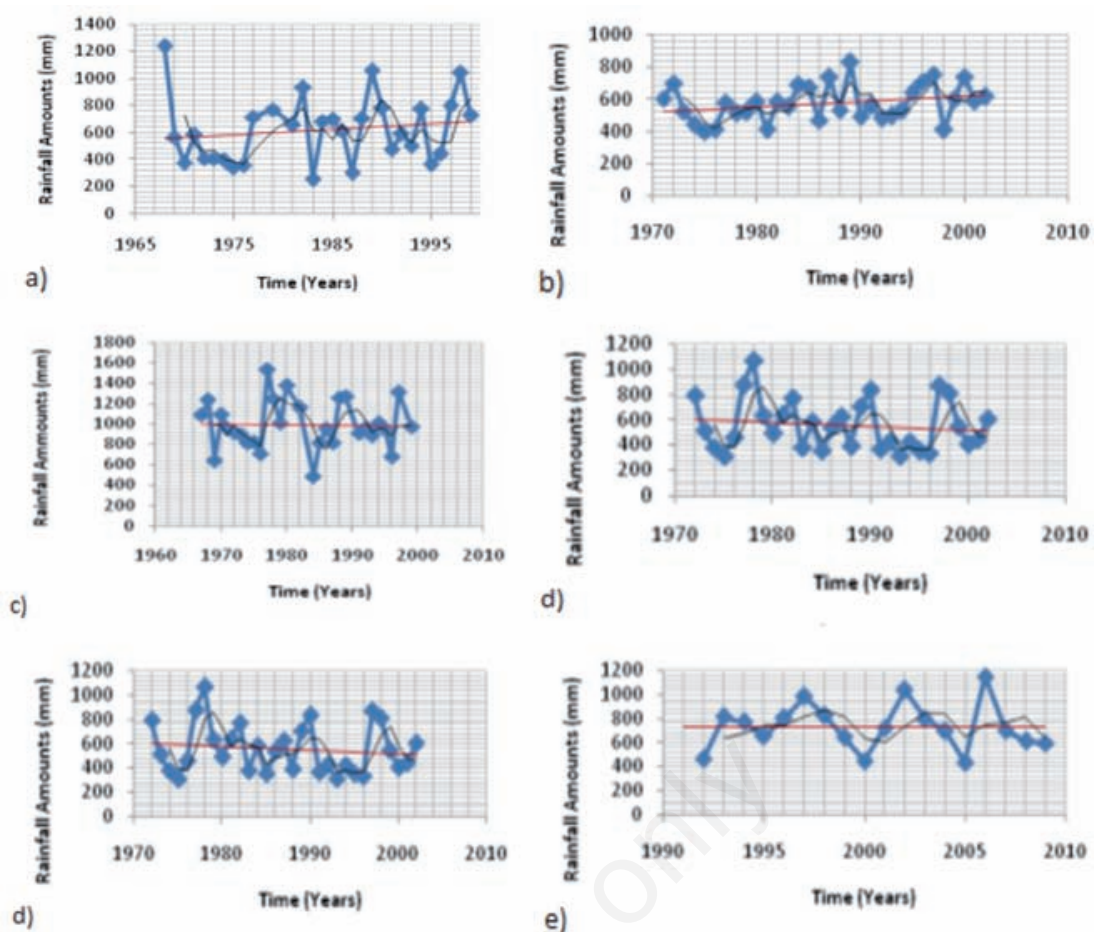

Figure 2. Observed rainfall (blue), locally weighted regression (black) and trend of unsmoothed annual precipitation totals (continuous red line) for a) Makindu b) Dodoma, c) Dagoretti, d) Same, and e) Narok synoptic stations in East Africa.
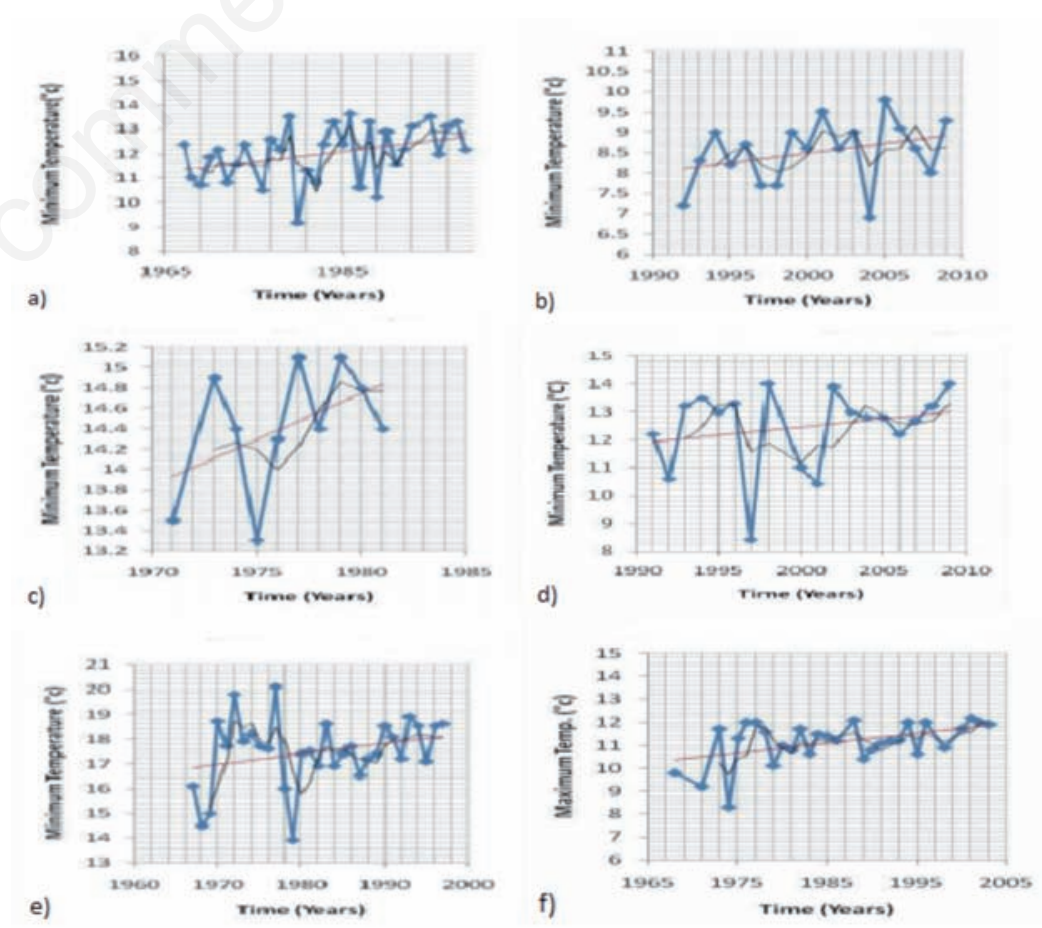

Figure 3. Observed minimum temperature (blue), locally weighted regression (black) and unsmoothed annual minimum temperature trend (continuous red line) for a) Dagoretti, b) Kericho, c) Kigoma, d) Kisumu, e) Lodwar, and f) Makindu synoptic stations in East Africa. 
data records were used to compute MannKendal trend test statistics, a non-parametric test statistics used to detect the trend of data set used with positive and negative values indicating an increasing or decreasing trend respectively as shown in equation 1. Daily rainfall and temperature records were used to compute indices of climate change extremes with RClimDex (1.0) - which comprised 27 core indices ${ }^{26}$ as shown in Appendix B, and were selected for analysis. The computed indices of climate change extremes were aimed at providing information for climate change monitoring and detection.

$$
S=\sum_{i=1}^{n-1}\left[\sum_{j=i+1}^{n} \operatorname{sgn}\left(R_{i}-R_{l}\right)\right]
$$

In equation $1, n$ represents data points, $R_{\mathrm{i}}$ represents the rank of data points at time $i$, and $s g n$ is an acronym for sign which can either be positive or negative.

Climate change and variability were observed through changes in extreme values over EA based on perturbations in large scale forcing (SOI, SA) and monthly rainfall totals. Perturbations were computed based on moving average method. The moving average method implemented by a macro program identifies three highest values (extremes) in the first block where each block has a length of three years. It also computes the relative frequency of the highest values in the first block to the whole data set. It then shifts by one step and repeats the whole procedure. As it moves, it checks how the maximum values in each block relate to other values in the whole dataset series. The resulting time series of perturbations of large scale variability and rainfall totals were then compared to identify how extremes were changing and cluster stations with similar characteristics in order to draw homogeneous zones of change over EA.

\section{Results and Discussion}

\section{Trend analysis based on graphical method}

Patterns of unsmoothed annual time series with a fitted trend line and locally weighted regression for total precipitation, minimum and maximum temperature, consecutive dry and wet days are shown in Figures 2-6. Figure 2 shows precipitation annual totals (PRCPTOT) for selected stations. Notably, annual total precipitation had mixed signals. Dodoma and Makindu showed increasing trends, while Dagoretti, Kericho, Kigoma, Kisumu, Lodwar, Narok and Same showed decreasing trends. Figures 3 and 4 show the trend of minimum temperature (TNn) and maximum tempera-
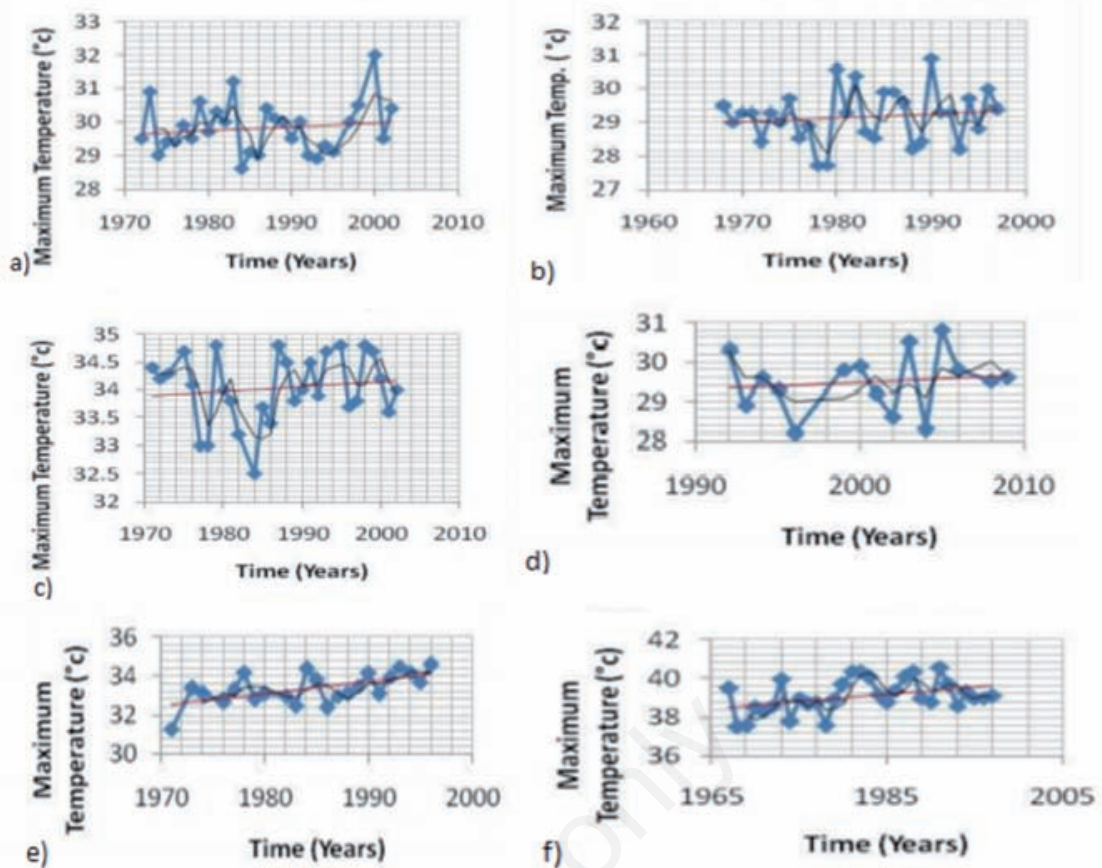

Figure 4. Observed maximum temperature (blue), locally weighted regression (black) and unsmoothed annual maximum temperature trend (continuous red line) for a) Bukoba, b) Dagoretti, c) Dodoma, d) Kericho, e) Kigoma, and f) Lodwar synoptic stations in East Africa.
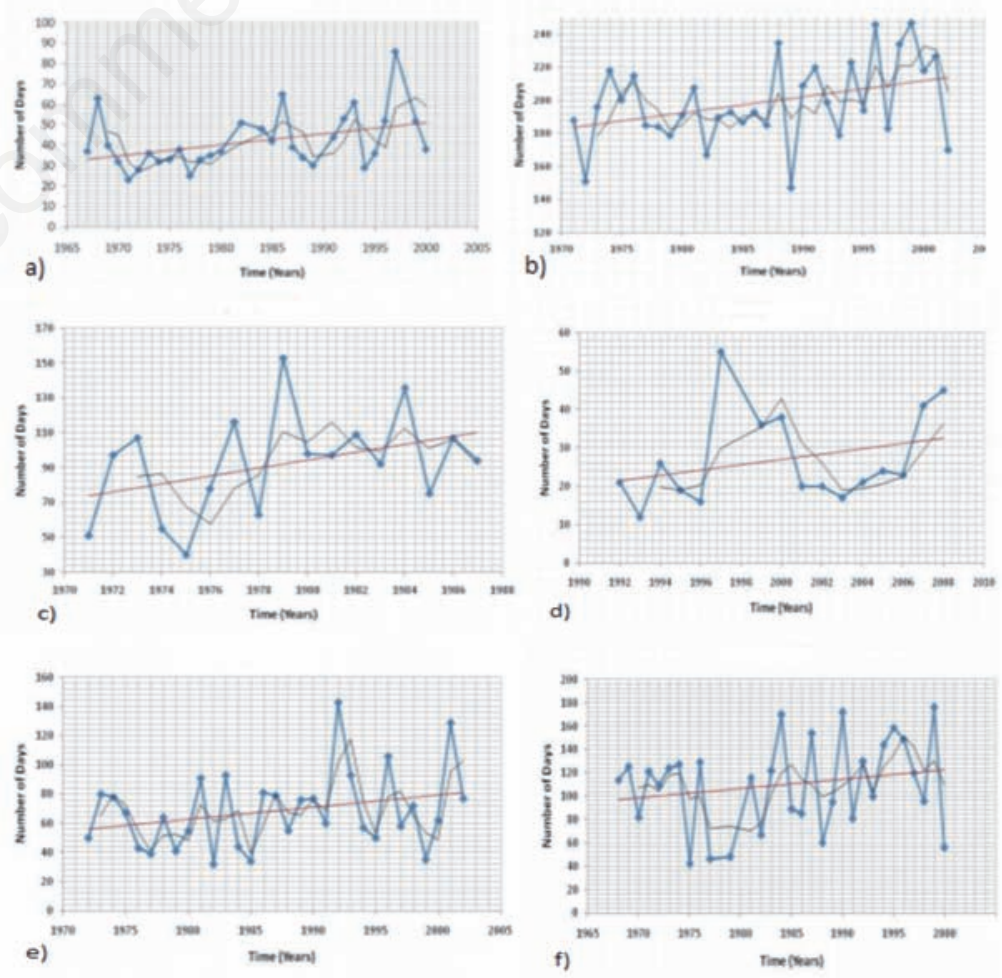

Figure 5. Observed dry days (blue), locally weighted regression (black) and unsmoothed annual consecutive dry days trend (continuous red line) for a) Dagoretti, b) Dodoma, c) Kigoma, d) Kisumu, e) Same and f) Makindu synoptic stations in East Africa. 
ture (TXx) to be increasing. The trend for maximum temperature has been increasing. The annual trends for the observed consecutive dry days (Figure 5) and consecutive wet days (Figure 6) showed an increasing trend.

\section{Trend analysis based on regression of precipitation indices}

Results of regression for daily precipitation indices based on rainfall totals are shown in Table 1 . Monthly maximum one day precipitation (RX1day), monthly maximum consecutive five day precipitation (RX5day), annual count of days when precipitation is greater than 10 mm (RX10) and annual count of days when precipitation is greater than $20 \mathrm{~mm}$ (RX20) were considered. The result showed an increasing trend at 54 and 50\% for RX1day and RX5day, respectively. A decreasing trend at 69 and $38 \%$ for RX10 and RX 20 , respectively was realized. There was an increasing trend for indices RX10 and RX20 at 15 and 46\%, respectively.

Analysis of annual total precipitation index (PRCPTOT) showed a general decline with $69 \%$ of stations indicating a decreasing trend. Annual total precipitation greater than the $95^{\text {th }}$ percentile (i.e. very wet days) was represented as R95p, and annual total precipitation greater than the $99^{\text {th }}$ percentile (i.e. extremely wet days) represented by $\mathrm{R} 99 \mathrm{p}$ showed a tendency of significant increasing trend at $46 \%$ of the stations. The results for consecutive dry days (CDD) showed increasing trend at $62 \%$ of the stations considered, while $23 \%$ of the stations showed a decreasing trend. In the case of consecutive wet days (CWD), $46 \%$ of the stations had an increasing trend, while $38 \%$ of the stations showed a decreasing trend.

\section{Trend analysis based on regression of temperature indices}

Regression results for temperature indices with daily observed minimum and maximum temperature are shown in Table 2. Majority of the stations had warm spell duration indicator (WSDI) showing an increasing trend, while cold spell duration indicator showed a decreasing trend (CSDI), an indication of more warm duration occurring over the region compared to cold spells. Furthermore, significant increases in the absolute annual daily maximum (TXX) and minimum temperatures (TNn) are indicated by most stations showing increasing trend. Individual stations also showed spatial coherence for the TN90p index, that is, the frequency of nights warmer than the $90^{\text {th }}$ percentile. The representative stations indicated a significant increasing trend in the number of warmer nights over the periods under consideration with only two stations showing a decreasing trend. There was increased frequency of hot days and warm nights per year showed by the increasing number of days and nights exceeding the TX90p and TN90p, respectively. There was an increasing trend for all stations with warm days except for one out of the eleven stations. There were also large reductions in the frequency of cold nights and cool days over the years with a majority of the stations indicating a decreasing trend as shown by TN10p and TX10p, respectively.

The trend for warm nights showed an increase in the number of warm nights (TN90p) as eight of the stations showed an increasing trend. For cool night index (TN10p), eight out of eleven stations, had a decreasing trend. The number of cool (TX10p) days is decreasing, as shown by six out of the eleven stations having negative trend.

\section{Trend analysis based on Mann- Kendall tests}

The behavior of trend was analyzed using the Mann-Kendall non parametric test at various significance levels, i.e. at 10,5 and $1 \%$ as shown in Table 3 for selected stations. MannKendall rank test showed positive values for nine stations, which implies increasing trend with time. However, at different significance levels, the magnitude of the test statistic varied. Although Lodwar and Kigoma showed negative values implying a decreasing trend, the magnitude was not significant. Masindi station had the highest value computed at 2.58 at a significance level of $1 \%$. Eldoret station had the lowest value of 1.32 at a significance level of $10 \%$.

\section{Observed climate change and vari- ability}

Perturbation due to large scale variability (SOI and SA) showed that the magnitude and frequency of extreme values were with cycles of 40 to 60 years (Figure 7). SOI (Figure 7a) and SA (Figure 7b) showed decreasing and
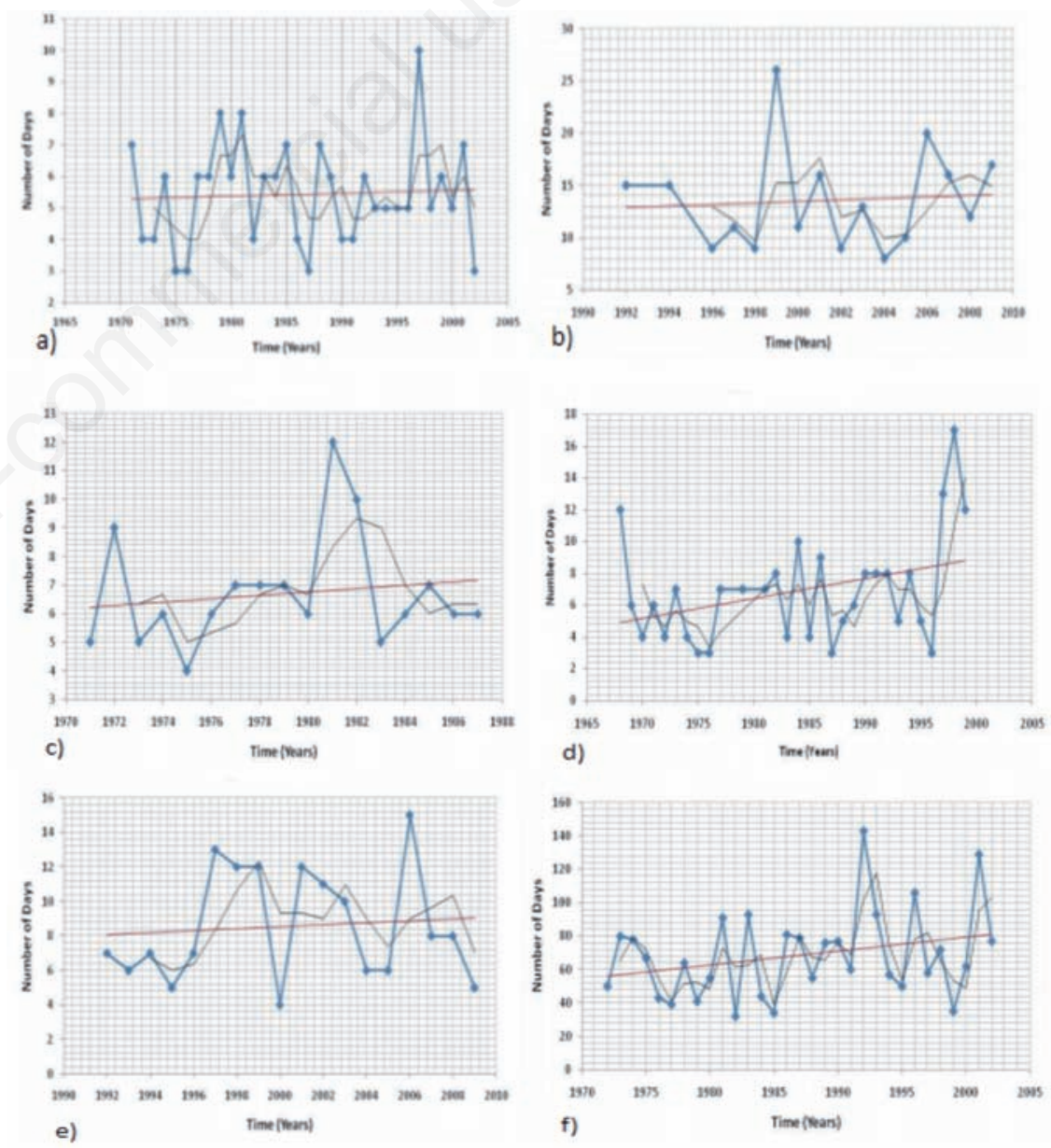

Figure 6. Observed wet days (blue), locally weighted regression (black) and unsmoothed annual consecutive wet days trend (continuous red line) for a) Dodoma, b) Kericho, c) Kigoma, d) Makindu, e) Narok, and f) Same synoptic stations in East Africa. 

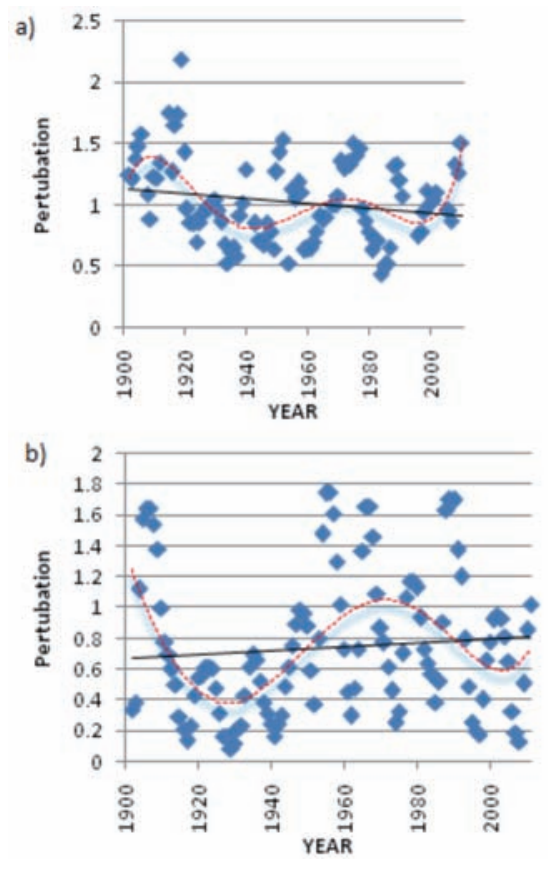

Figure 7. Perturbation due to large scale variability of a) southern oscillation index and b) sunspot activity.

increasing trends, respectively. Clustered synoptic rainfall stations (Figure 8) showed similarities and clustered as either the dry continental (SOI), wet continental (both SOI and SA), coastal (with SA dominant) or lake Victoria (unique to both SOI and SA) areas, as indicated in Figure 8. These areas indicate homogeneous zones of change over EA.

\section{Conclusions}

Trend analysis of the past and present patterns of rainfall and temperature extremes over equatorial EA based on graphical, regression and non-parametric tests approaches noted that annual total rainfall has been decreasing. Heavy and extreme precipitation rates are confined within short spells which are already wet days. The extreme precipitation confined in the upper five percentiles is observed to be increasing with time. Furthermore, an increase in maximum temperature extremes was observed and declining minimum temperature extremes with a statistically significant rise in the number of hot days and warm nights and a decrease in number of cool days and cold nights. The spacetime patterns of the observed changes were largely not well organized.

The observed climate change and variability indicates that extreme values are changing with increasing frequency and magnitude. Based on large scale variability, homogeneous
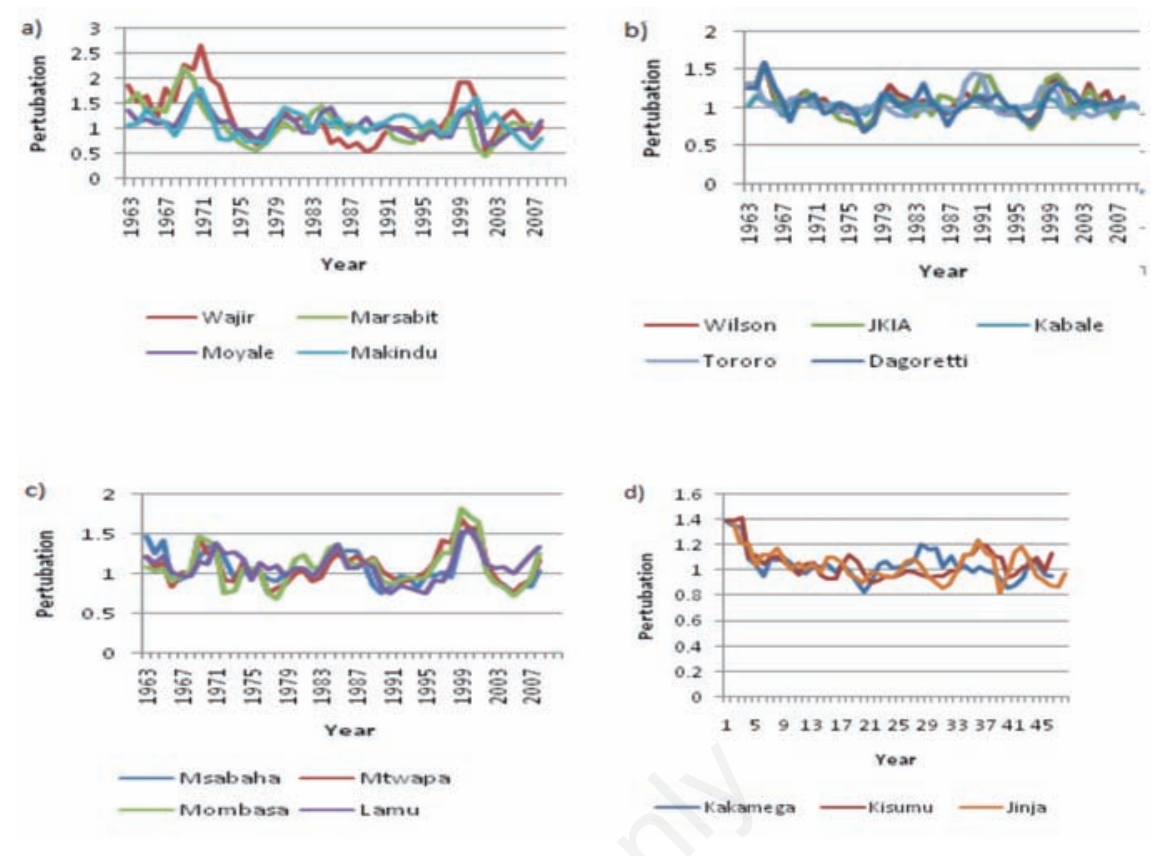

Figure 8. Perturbations of observed rainfall over a) dry continental, b) wet continental, c) coastal and d) lake Victoria areas.

zones of change were identified over EA. Synoptic rainfall stations (Figure 8) showed similarities and clustered as either in the coastal (with SA dominant), lake Victoria (unique to both SOI and SA), dry continental (SOI) or wet continental areas (both SOI and SA). These areas indicate homogeneous zones of change over EA. To provide reliable clusters of observed homogeneous zones of climate change, further analysis with more large scale forcing should be used.

\section{References}

1. Leary N, Adejuwon J, Barros V, Batimaa P. A stitch in time: general lessons from specific cases. In: Leary N, Adejuwon J, Barros V, Burton I, Kulkarni I, eds. Climate change and adaptation. London: Earthscan Publ.; 2008. pp 1-28.

2. IPCC. Climate change 2001: the scientific basis. Cambridge: Cambridge University Press; 2001.

3. Malhi Y, Wright J. Spatial patterns and recent trends in the climate of tropical rainforest regions. Philos T Roy Soc B 2004;359:311-29.

4. Hulme M, Doherty R, Ngara T, New M. Global warming and African climate change. In: Low PS, ed. Climate Change and Africa. Cambridge: Cambridge University Press; 2005. pp 29-40.

5. King'uyu SM, Ogallo LA, Anyamba EK.
Recent trends of surface minimum and maximum temperatures over Eastern Africa. J Climate 2000;13:2876-85.

6. Schreck CJ, Semazzi FHM. Variability of the Recent Climate of Eastern Africa. Int J Climatol 2004;24:681.701.

7. Pandey DN, Gupta AK, Anderson DM. Rainwater harvesting as an adaptation to climate change. Curr Sci India 2003;85:4659.

8. Few R, Ahern M, Matthies F, Kovats S. Floods, health and climate change: a strategic review. Working paper 63 . Norwich: University of East Anglia ed.; 2004. pp 138.

9. Tarhule A, Woo M. Changes in rainfall characteristics in northern Nigeria. Int $\mathrm{J}$ Climatol 1998;18:1261-71.

10. Trenberth KE, Jones PD, Ambenje P, et al. Observations: surface and atmospheric climate change. In: IPCC, ed. Climate change 2007: the physical science basis. Cambridge: Cambridge University Press; 2007. pp 235-336.

11. Obasi GOP. The impacts of ENSO in Africa. In: Low PS, ed. Climate Change and Africa. Cambridge: Cambridge University Press; 2005. pp 218-230.

12. Kabat P, Schulze RE, Hellmuth ME, Veraart JA. Coping with impacts of climate variability and climate change in water management: a scoping paper. Wageningen: Dialogue on Water and Climate ed.; 2002. pp 114.

13. IPCC. Climate change 2007: the physical 
science basis. Cambridge: Cambridge University Press; 2007.

14. Kerandi NM, Omotosho JA. Seasonal rainfall prediction in Kenya using empirical methods. J Kenya Meteorological Soc 2008;2:119-28.

15. Ininda JM, Muhati FD, Opijah FJ. Relationship between ENSO parameters and the trends and periodic fluctuations in east African rainfall. J Kenya Meteorological Soc 2007;1:20-43.

16. Ngaira JKW. Impact of climate change on agriculture in Africa by 2030. Sci Res Essays 2007;2:238-43.

17. Craig MH, Kleinschmidt I, Nawn JB, et al. Exploring 30 years of malaria case data in KwaZulu-Natal, South Africa: part I. The impact of climatic factors. Trop Med Int Health 2004;9:1247-57.

18. Patz JA, Campbell-Lendrum D, Holloway T,
Foley JA. Impact of regional climate change on human health. Nature 2005;438:310-7.

19. IPCC. Managing the risks of extreme events and disasters to advance climate change adaptation. Cambridge: Cambridge University Press; 2012.

20. Palmer MA, Liermann CR, Nilsson C, et al. Climate change and the world's river basins: anticipating management options. Front Ecol Environ 2008;6:81-9.

21. Folland CK, Karl TR. Observed climate variability and change. In: IPCC, ed. Climate change 2001: the scientific basis. Cambridge: Cambridge University Press; 2001. pp 99-182.

22. Omondi PA. Teleconnections between decadal rainfall variability and global sea surface temperatures and simulation of future climate scenarios over East Africa.
PhD Thesis. Nairobi: Department of Meteorology, University of Nairobi ed.; 2010.

23. Bowden J, Semazzi FHM, Anyah R, Schreck C. Intraseasonal to decadal variability of the greater horn of Africa. Raleigh, NC: North Carolina State University; 2005.

24. Anyah R0, Semazzi FHM. Variability of East African rainfall based on multiyear RegCM3simulations. J Climatol 2006;27: 357-71.

25. Indeje M, Semazzi FHM. Relationships between QBO in the lower equatorial stratospheric zonal winds and East African seasonal rainfall. Meteorol Atmos Phys 2000;73:227-44.

26. Zhang X, Yang F. RClimDex (1.0) user guide. Downsview, Ontario: Climate Research Branch Environment ed.; 2004. 